\section{Access to new drugs for rare disorders in Canada}

McMillan and Campbell believe that Canada needs a regulatory framework for the introduction of orphan drugs for rare disorders. ${ }^{1}$ We agree. However, the need is unlikely to be met in the foreseeable future because, in October 2017, the present federal government deleted from the Health Canada website, without notice or consultation, all references to the previous government's 2012 Orphan Drug Regulatory Framework. ${ }^{2}$

Access to a new drug for a rare disorder depends not only on its regulatory approval, but also on the drug successfully passing the Canadian Agency for Drugs and Technologies in Health's (CADTH's) Common Drug Review process, negotiations regarding price between the pan-Canadian Pharmaceutical Alliance (PCPA) and the manufacturer, the Patented Medicine Prices Review Board price-assessment process, and individual drug-plan evaluations and negotiations with the manufacturer.

Although CADTH has considered establishing a focused review process for drugs for rare disorders, it chose to integrate review of these drugs into the usual Common Drug Review process. Nevertheless, Richter and colleagues from CADTH recently analyzed Common Drug Review recommendations for drugs for rare disorders made between 2004 and 2016 and suggested that it may be inappropriate to apply the same appraisal standards to drugs for ultra-rare disorders (those with a prevalence of $\leq 1$ per 100000$).^{3}$

A different appraisal standard is appropriate for all drugs for rare disorders, but the likelihood of one being created by CADTH is low. The earlier lack of interest shown by CADTH in establishing a separate review process for drugs for rare disorders and the recent integration of CADTH and the PCPA, in which they attend each other's meetings and share confidential information about manufacturers' submissions ${ }^{4}$ (which leads to a negative reimbursement recommendation resulting in no $\mathrm{pCPA}$ negotiation and a positive one setting up negotiating factors - usually a substantial price reduction), ${ }^{5}$ indicate that the government public drug plans that own, fund and manage CADTH and the $\mathrm{PCPA}^{6}$ are not in favour of a separate appraisal standard for drugs for rare disorders.

Canadian government officials are instead focused on a mantra of "affordability, accessibility and appropriate use of prescription drugs." "The federal government is expanding the already extensive deterrents to the introduction of new drugs into Canada with a planned $77 \%$ increase in the regulatory review fee for new drugs ${ }^{8}$ and sweeping changes to the Patented Medicines Regulations, ${ }^{9,10}$ which will delay or deny patient access to new drugs, especially drugs for rare disorders. Rather than providing hope to patients needing drugs for rare disorders, Canadian governments appear to be moving toward a basic "pharmacare" system built on a formulary of inexpensive genericized drugs and a relatively small, restrictedaccess list of expensive drugs, including drugs for rare disorders, available from manufacturers willing to negotiate substantial price reductions. ${ }^{11,12}$

Canadian governments and their associated organizations should instead be developing inventive and coherent nationwide policies to balance timely and fair access to drugs for rare disorders with appropriately competitive pricing negotiations so that drugs are accessible to Canadians who need them. Affordability and accessibility should be implemented together, not as one or the other. Simply erecting more barriers to deter or delay pharmaceutical manufacturers from bringing new drugs for rare disorders to Canada fails to improve the lives of patients and is not the solution to high drug prices.

\section{Nigel S. Rawson MSc PhD}

Pharmaceutical policy researcher, Eastlake Research Group, Oakville, Ont., and Fraser Institute, Vancouver, BC

\section{John Adams BA}

Cofounder, president and CEO, Canadian PKU and Allied Disorders Inc., Toronto, Ont., and Best Medicines Coalition, Toronto, Ont.
Cite as: CMAJ 2018 July 9;190:E840. doi: 10.1503/cmaj.69340

\section{References}

1. McMillan HJ, Campbell C. We need a "made in Canada" orphan drug framework. CMAJ 2017; 189:E1274-5.

2. Forrest M. Health Canada gives 'kiss of death' to planned policy for rare-disease drugs. National Post [Toronto] 2017 Oct. 16. Available: http://national post.com/news/politics/health-canada-gives-kiss -of-death-to-planned-policy-for-rare-disease-drugs (accessed 2018 Mar. 1).

3. Richter T, Janoudi G, Amegatse W, et al. Characteristics of drugs for ultra-rare diseases versus drugs for other rare diseases in HTA submissions made to the CADTH CDR. Orphanet $J$ Rare Dis 2018;13:15.

4. CDR update - Issue 119. Ottawa: Canadian Agency for Drugs and Technologies in Health; 2016. Available: www.cadth.ca/cdr-update-issue -119 (accessed 2018 Mar. 1).

5. Rawson NSB. Health technology assessment of new drugs for rare disorders in Canada: impact of disease prevalence and cost. Orphanet J Rare Dis 2017;12:59.

6. Rawson NS, Adams J. Do reimbursement recommendation processes used by government drug plans in Canada adhere to good governance principles? Clinicoecon Outcomes Res 2017;9:721-30.

7. Remarks from the Honourable Jane Philpott, Minister of Health, to the Economic Club of Canada - May 16, 2017. Affordability, accessibility \& appropriate use of prescription drugs [speech]. Ottawa: Health Canada; 2017. Available: www.canada.ca/en/health-canada/news/ 2017/05/economic_club_ofcanada-may 162017 .html (accessed 2018 Mar. 1).

8. Fee proposal for drugs and medical devices (for consultation). Ottawa: Health Canada; 2017. Available: www.canada.ca/en/health-canada/programs/ consultation-fee-proposal-drugs-medical-devices/ drug-medical-device-fee-change-proposal.html (accessed 2018 Mar. 1).

9. Regulations amending the Patented Medicines Regulations. Canada Gazette [Ottawa] 2017; Vol. 151: No. 48. Available: http://canadagazette.gc. ca/rp-pr/p1/2017/2017-12-02/html/reg2-eng.html (accessed 2018 Mar. 1)

10. Rawson NSB. Ottawa's revisions to drug-pricing review board will delay or prevent access to new drugs. Vancouver: Fraser Institute; 2018. Available: www.fraserinstitute.org/article/ottawas -revisions-to-drug-pricing-review-board-will-delay -or-prevent-access-to-new-drugs (accessed 2018 Mar. 1).

11. Rawson NSB. What does the new Ontario pharmacare plan offer children and young adults with rare disorders? J Popul Ther Clin Pharmacol 2017;24:90-8.

12. Harris K. Pharmacare won't be free for all Canadians, Bill Morneau says. CBC News 2018 Feb. 28. Available: www.cbc.ca/news/politics/morneau -budget-2018-pharmacare-1.4555186 (accessed 2018 Mar. 1).

Competing interests: None declared. 